\title{
DE MEDIOS E INTERMEDIAS: \\ MEDIOS DE COMUNICACIÓN EN CIUDADES INTERMEDIAS
}

María Eugenia Iturralde ${ }^{1}$

\section{Introducción}

Este trabajo se enmarca en una investigación más amplia realizada en Argentina, que aborda la aplicación de políticas de comunicación en ciudades intermedias de la provincia de Buenos Aires (tomando los casos de Azul, Olavarría y Tandil) en el contexto de discusión, sanción y aplicación de la Ley de Servicios de Comunicación Audiovisual (LSCA) $\mathrm{N}^{\circ}$ 26.522, en el período 2004-2015. Estos procesos son analizados teniendo en cuenta: por un lado, la perspectiva de la Economía Política de la Comunicación en América Latina, incluyendo los trabajos enmarcados en las propuestas participativas de la comunicación y el desarrollo que analizan conceptos como acceso, participación y autogestión de medios de comunicación (Servaes, 2000); y por otro, al referirnos a Azul, Olavarría y Tandil lo hacemos caracterizando a estas ciudades como ciudades intermedias o de rango medio, porque estas nociones nos permiten analizar a las ciudades como núcleos integrados a una red de relaciones, nacionales e internacionales, atravesadas por dimensiones simbólicas e ideológicas.

El objetivo de este artículo es centrarnos en las conceptualizaciones sobre ciudades intermedias o de rango medio, provenientes de la Antropología Urbana, teniendo en cuenta los análisis efectuados por el núcleo de investigación PROINCOMSCI en el que se inscribe la producción, para ponerlas en diálogo con los procesos analizados sobre medios de comunicación.

\section{Sistema de medios de comunicación en Argentina}

En Argentina ha primado el modelo comercial en los medios de comunicación (Mastrini, 2006), profundizándose esa estructura en la década de 1990 de la mano de la concentración y la extranjerización de la propiedad de los mismos. La adopción de ese modelo da lugar a la centralización geográfica; desde esta conceptualización se observa

\footnotetext{
${ }^{1}$ Universidad del Centro de la Provincia de Buenos Aires, Argentina.
} 
que la mayor parte de la producción audiovisual se realiza en la Ciudad Autónoma de Buenos Aires (CABA). Esta fuerte lógica comercial ha obstruido diversas iniciativas tendientes a introducir modificaciones en el sistema de comunicación, siendo los intereses del mercado los que se han interpuesto a políticas que conciban a la comunicación como un Derecho Humano y posicionen al Estado como garante del mismo. El siglo XXI dio lugar a una serie de iniciativas, surgidas tanto de la sociedad civil como del Estado, que intentaron buscar un nuevo ordenamiento del sistema de medios de comunicación. Uno de estos es la sanción de la LSCA.

La concentración no es un fenómeno particular de Argentina, es una problemática latinoamericana. Martín Becerra (2014) afirma que la historia de la producción y distribución de información y entretenimientos masivos en América Latina se caracteriza por una serie de continuidades sostenidas a lo largo del siglo XX: protagonismo de la lógica comercial, ausencia de servicios públicos no gubernamentales, concentración de la propiedad del sistema de medios, centralización de la producción de contenidos informativos y de entretenimiento en los principales centros urbanos de cada país, y medios escasamente regulados pero fuertemente controlados por las relaciones informales mantenidas entre los grandes grupos de comunicación y los diferentes gobiernos tanto civiles como militares.

Sin embargo el cambio de siglo trajo novedades en materia de radiodifusión. En los primeros años del siglo XXI Latinoamérica atravesó una serie de modificaciones en el modelo comercial de medios de comunicación. Mencionaremos dos de estas: en primer lugar fue posible dictar nuevas regulaciones para el sector, generalmente posicionadas en contra de la concentración de la propiedad y la extranjerización, y en segundo término el Estado adoptó el lugar de emisor y gestor de la comunicación.

\footnotetext{
Varios gobiernos de la región enunciaron su intención de modificar el statu quo en las industrias de la comunicación y la cultura: notablemente, se trata de políticas que pretenden alterar su régimen de propiedad, sus modos de financiamiento y las posibilidades de acceso a ellas por parte de diferentes actores sociales. Varios gobiernos de la región también innovaron en el cuestionamiento de la labor mediadora que ejercieron durante el siglo XX (y parte del siglo anterior) las industrias culturales. (Becerra, 2014: 67)
}

Frente a las rupturas planteadas al modelo comercial de medios de comunicación del nuevo siglo, que cuestionan la concentración y la centralización, y las señalan como obstáculo para la democratización, surge un interrogante que constituye nuestro problema de investigación: ¿Qué sucedió en materia de políticas de comunicación en 
tres ciudades intermedias de la provincia de Buenos Aires en el contexto de discusión, sanción y aplicación de la LSCA $\mathrm{N}^{\circ} 26.522$ de la Nación Argentina, período comprendido entre 2004 y 2015 ?

\section{Ciudades intermedias}

El análisis se efectúa en las ciudades de Olavarría, Azul y Tandil. Las dos primeras se ubican geográficamente en el centro y la última al centro-sudeste de la provincia de Buenos Aires. Las ciudades analizadas son de tamaño medio-medio, de base económica preponderantemente agropecuaria e industrial-minera; no pertenecen a una región metropolitana y tampoco se posicionan como centros rurales, lo que les confiere el carácter intermedio entre ambos términos.

Esta noción de ciudad intermedia o de rango medio permite analizar a las ciudades como núcleos integrados a una red de relaciones nacionales e internacionales atravesadas por las dimensiones simbólicas e ideológicas (Gravano, 2005; Boggi y Galván, 2016). En las décadas de 1950 y 1960, desde la Urbanística y la Geografía, fue acuñada la noción de ciudad media, con la que se conceptualiza a las ciudades que poseen entre 50.000 y 500.000 habitantes, como meros espacios físicos. Esa noción se desprende de indicadores estructurales y de funcionalidad. Pero desde nuestra perspectiva la ciudad se inscribe en un contexto y posee dinámicas simbólicas que constituyen la especificidad de los centros urbanos de rango intermedio (Silva y Boggi, 2016).

¿Por qué analizar estas ciudades? Cuando se reflexiona sobre lo urbano, en ámbitos académicos y/o profesionales, los debates y estudios suelen concentrarse en los fenómenos que acontecen en las grandes ciudades, dejando a un lado la posibilidad de construir a las ciudades medias y pequeñas como objeto de análisis (Boggi y Galván, 2016). Pero gran parte de la población urbana mundial vive en ciudades medias y pequeñas que no exceden los 500.000 habitantes, y esos centros urbanos permiten que gran parte de la población mundial acceda a servicios, bienes e infraestructura (Llop Torné, 1999). Lo urbano se suele preconcebir desde un modelo a escala metropolitana no sólo desde ámbitos académicos, sino también desde el sentido común y la gestión político-institucional, repercutiendo en la especificidad del funcionamiento de los sistemas institucionales y en el cumplimiento de sus propósitos (Gravano, 2016). 
Ana Silva y Ariel Gravano definen al sistema urbano como:

\begin{abstract}
...el conjunto de aparatos y dispositivos institucionales para la provisión pública de consumos colectivos, en su dimensión espacial y su consecuente valoración material y simbólica. No es un mero contexto o recipiente de problemáticas generales, sino un sistema de sistemas satisfactores de servicios ciudadanos (de infraestructura, equipamientos, vivienda, comunicación, regulación espacial, educativos, judiciales, de salud, empleo, mediáticos, etc.) con base y distribución física en el espacio y trascendencia temporal y que hacen al valor de uso de la ciudad misma. (Silva y Gravano, 2017: 176-177).
\end{abstract}

La Provincia de Buenos Aires está dividida geográficamente en 135 municipios. El mayor número de los mismos, 83, no supera los 50.000 habitantes, y -de acuerdo con los datos del Censo 2010- de los/as 15.625.084 de bonaerenses, 8.578.572 viven en ciudades medias. Si las políticas públicas, el sentido común y las reflexiones académicas no dan lugar a lo urbano no metropolitano, es muy poco probable que las problemáticas de gran parte de la población sean abordadas desde sus particularidades. Allí reviste la necesidad de abordarlas y analizarlas considerando sus especificidades. Los sistemas institucionales suelen asumirse como universales respecto del derecho moderno al acceso a los consumos colectivos, y toman como base los contextos metropolitanos.

El enfoque propuesto por el grupo de investigación que dirige Gravano supone que lo urbano es el sistema que articula el funcionamiento de los consumos colectivos en su dimensión espacial y sus respectivos imaginarios, no es meramente el soporte físico infraestructural de la ciudad. Más de dos décadas de investigaciones, efectuadas sobre la base de estudios de caso realizados con metodología etnográfica, en ciudades intermedias de la provincia de Buenos Aires permitieron avanzar en cuatro hipótesis teóricas que guían los análisis: palimpsesto urbano, homeostasis múltiple, metropolismo y tramas del poder (Gravano, 2016).

El palimpsesto surge de la pregunta sobre la relación entre la espacialidad y la temporalidad de los imaginarios del rango medio. El interrogante inicial

Apuntaba a la relación entre la unidad identitaria de las ciudades intermedias, establecida sobre la base de una supuesta homogeneidad, y su real heterogeneidad marcada por diferentes formas de discriminación y segregación socio-espacial" (íd.:76). 
En estas ciudades se reconstruye la coexistencia de imágenes identitarias superpuestas, que proceden de diferentes períodos históricos y tienen base en diversas fuentes de enunciación. Estas imágenes se componen como un papiro antiguo que parcialmente se borra y se reescribe sobre texturas de trazos anteriores que no han desaparecido del todo. Las imágenes superpuestas son procesos en los cuales distintos actores producen imágenes que no desaparecen, se superponen y ninguna borra totalmente a las anteriores. Una imagen común identificada es la de ciudad de frontera; estas localidades dan cuenta de una construcción identitaria en su condición de frontera con el indio al sur del Río Salado en expansión durante el siglo XIX. Otra es la de tribalismos blancos, que destaca la preponderancia étnicamente blanca y los modelos culturales europeizantes. El imaginario de ciudad de frontera y el de los tribalismos blancos coinciden en la necesidad de segregar lo no blanco, lo no europeo. En el siglo $\mathrm{XX}$ las imágenes emblemáticas se van a conformar en torno a los principales componentes de los sistemas productivos (Gravano, 2005).

Olavarría es tipificada como ciudad del cemento, ciudad del trabajo, en la segunda mitad del siglo esas imágenes la sitúan como polo productivo, fuente de progreso. Las políticas neoliberales de la década de 1990 dieron lugar a procesos de fragmentación en la estructura social urbana y en el imaginario. Los índices de desempleo pusieron en jaque la imagen de la ciudad del trabajo. Actualmente existen intentos de reconversión imaginaria, como por ejemplo la ciudad tuerca, en referencia a los logros automovilístico de los hermanos Emiliozzi en década de 1960, a bordo de su auto denominado La Galera (Boggi y Silva, 2016).

Tandil está enclavada en pleno macizo serrano, y nutre su imaginario identitario del turismo. La ciudad de las sierras, la ciudad de la naturaleza, asociada a tranquilidad, paz; como opuesta a la metrópolis. En Semana Santa tiene una fuerte oferta de turismo religioso en el Vía Crucis del Monte Calvario y todo el año ofrece alternativas de turismo de "aventura". Un intento de reconversión imaginaria reciente se dio con la construcción de una Piedra Movediza artificial. Las raíces turísticas de Tandil pueden encontrarse en la presencia de una mítica Piedra Movediza que desapareció físicamente a principios del siglo XX. En 2007 la ciudad de la naturaleza emplazó su Piedra Movediza “artificial” en las sierras (Boggi y Silva, 2016). 
En el caso de Azul sus imágenes emblemáticas la presentan como un centro agro-ganadero y militar. Acuñó imaginarios positivos al considerarse una ciudad "cultural" y "profesional", haciendo referencia a las profesiones liberales, y delimitándose de las ciudades consideradas “obreras" como Olavarría. La reconversión de los últimos años la posiciona como ciudad de la cultura, ciudad cervantina (Boggi, 2016).

La segunda hipótesis del imaginario medio es denominada por Gravano homeostasis múltiple, y consiste en suponer la tendencia al equilibrio como condición previa y ulterior a todo proceso social (Gravano, 2016: 83). En el imaginario hegemónico se pre-concibe a la ciudad como un organismo que necesita un grado mínimo de equilibrio interno para subsistir. Desde esta perspectiva, homeostática, se piensa la provisión de servicios públicos de consumo colectivo, presuponiendo el equilibrio y no la contradicción dialéctica. La racionalidad hegemónica, entiende lo social de un modo integrista y deshistorizado. La noción de equilibrio lleva a la naturalización de estados socioculturales que suponen normalidad en la existencia de mayor equilibrio y patología en el conflicto. Los imaginarios de la discriminación y la segregación urbana encuentran su base en estos supuestos, en las ciudades intermedias por ejemplo llevan a señalar a ciertos sectores de la ciudad como barrios mancha (Gravano, 2005 $\mathrm{a}: 81$ ).

La tercera hipótesis, el metropolismo, sostiene que el modelo hegemónico naturaliza una concepción abstracta de lo urbano como idéntico a lo metropolitano, que se expresa en la agenda teórica de los estudios urbanos, el sentido común y la gestión político-institucional de los municipios (Gravano, 2016: 86).

La última hipótesis es un emergente reciente, la de las tramas del poder, que sostiene que en las ciudades intermedias se establecieron

\footnotetext{
... configuraciones de entramados vinculares de intereses y racionalidades entre sectores hegemónicos del empresariado, el sector público- político y franjas de profesionales que parecen funcionar como bloque histórico-institucional (Silva y Gravano, 2016: 50).
} 


\section{Claves de lo urbano medio y medios de comunicación}

Luego de repasar muy brevemente las cuatro hipótesis propuestas para analizar las ciudades intermedias, nos proponemos vincularlas con los sistemas de medios de comunicación de Azul, Tandil y Olavarría. Para ello utilizaremos como fuente mapas de industrias culturales del año 2015, entrevistas abiertas a actores vinculados a políticas de comunicación y datos históricos de los medios de comunicación.

En 2015, de mayo a diciembre, confeccionamos los mapas de industrias ${ }^{2}$ culturales de las tres ciudades analizadas, para efectuar un registro de los medios operativos al momento de cierre del período investigado. Si bien la investigación se centra en los medios audiovisuales (regulados por la LSCA) los mapas incluyen también a los medios gráficos, para dar cuenta de la concentración de propiedad de acuerdo a la titularidad. Los datos consignados en los mismos se extrajeron de oficinas de la Autoridad Federal de Servicios de Comunicación Audiovisual (AFSCA) de las ciudades de Olavarría y Tandil, el sitio web de AFSCA, la escucha de la amplitud modulada y la frecuencia modulada en diferentes horarios del día en las cabeceras de los partidos, consulta a informantes clave, publicaciones de medios de comunicación, Boletín Oficial de la República Argentina, sitio web NIC Argentina ${ }^{3}$ y búsquedas en Internet.

El Partido de Azul, según el mapa de industrias culturales, en el año 2015 no presentaba concentración de medios de comunicación de acuerdo con la propiedad, si bien tres medios pertenecen a una persona, estos no tienen un alto perfil comercial ${ }^{4}$. El tradicional medio de la ciudad es el diario El Tiempo; salió a la calle por primera vez el 9 de julio de 1933, y desde 1999 posee su sitio web.

En el Partido de Olavarría existen dos tradicionales medios de comunicación operativos, uno de ellos el diario El Popular, que lanzó su primera edición el 24 de junio de 1899. El otro LU 32 Radio Olavarría, inaugurada el 12 de diciembre de 1970

\footnotetext{
${ }^{2}$ Los mapas incluyen datos sobre: prestadoras de señal televisiva de pago, prestadoras de señal televisiva abierta, televisión por aire, televisión por suscripción, canales locales en Televisión Digital Abierta (TDA), radio $\mathrm{AM}$, radio $\mathrm{FM}$, prestadora de internet, sitio Web, publicación en papel, productora audiovisual registrada en la Autoridad Federal de Servicios de Comunicación Audiovisual (AFSCA), agencia de publicidad registrada en AFSCA y cine.

${ }^{3}$ Bajo la jurisdicción de la Dirección Nacional de Registro de Dominios de Internet.

${ }^{4}$ La radio FM del Pueblo nació en el año 2001, su línea editorial ha sostenido siempre fuertes críticas a las políticas neoliberales y su agenda informativa da lugar a los reclamos comunitarios. Para el año 2015 el sitio web FM del Pueblo era actualizado de manera irregular, una vez por semana en promedio. El Canal $5 \mathrm{Azul}$ TV es de aire y no posee contrato con las empresas que brindan servicio por suscripción.
} 
como filial de Radio Splendid de Capital Federal. En 1982 la AM local pasó a formar parte del Grupo Fortabat, hasta el año 2007 que fue transferida a su titular actual. Del crecimiento de estos medios se desprende la conformación de los dos grupos mediáticos que existen actualmente en la ciudad.

El Partido de Tandil al momento de efectuar el registro presentó tres grupos de medios: El Eco Multimedios, Multimedios La Voz y Radiodifusora Tandil S.R.L. El diario El Eco de Tandil salió a la calle el 30 de julio de 1882, fue fundado por Juan S. Jaca. En su aniversario número 100 fue vendido a Rogelio Adrián Rotonda, propietario y director hasta la actualidad. La nueva gestión fue adquiriendo y creando medios de comunicación, en el año 1998 inauguraron El Eco Digital que en 2015 fue rediseñado y actualmente se llama El Eco.com.ar. En el año 2000 lanzaron Eco Tv. En el año 2008 salió al aire en la frecuencia modulada 104.1 la radio Tandil FM. Editorial La Capital S.A, radicada en Mar del Plata, posee medios en diversas ciudades de la provincia de Buenos Aires e incluso comparte propietarios con el diario La Prensa de Ciudad Autónoma de Buenos Aires. Para el año 2015 en Tandil tenían la titularidad del diario La Voz de Tandil, editado desde el año 2000, el sitio web La voz de Tandil y la radio AM La Voz de Tandil, al aire desde 11 de febrero de 2008.El último grupo registrado es el de Radiodifusora Tandil S.R.L. El 1 de enero de 1970 se fundó LU 22 Radio Tandil, a la que algunos denominan "la radio madre", Modulada Radio Galáctica y posee un portal de noticias, LU 22 Radio Tandil.

Becerra (2014) señala que una de las continuidades de los medios de comunicación en América Latina en el siglo XX es la lógica comercial. El mapa de industrias culturales muestra que en Tandil y Olavarría siguen vigentes diarios creados a fines del siglo XIX y en Azul el tradicional diario salió a la luz en 1933. Las radios de amplitud modulada (AM) llegaron a Tandil y Olavarría en la década de 1970, en el caso de Azul en 1952. Las radios de frecuencia modulada (FM) empezaron a operar en las ciudades intermedias a fines de la década de 1970 y principios de la de 1980. La oferta de televisión de cable por suscripción surgió en la década de 1980 y fue acompañada por la creación de canales locales. Hasta ese momento podía sintonizarse por aire Canal 7 de CABA (de gestión estatal) pero con mucha dificultad en las tres ciudades. A diferencia de las radios FM, el resto de los medios de comunicación mencionados requiere una gran inversión inicial. La lógica comercial de los medios, en el caso de las

\footnotetext{
${ }^{5}$ Extraído de entrevistas a periodistas locales.
} 
ciudades intermedias, era universal. Para acceder a los canales de CABA -de aire y de gestión estatal- en buena calidad, era necesario pagar una suscripción. El acceso a los medios era posible para aquellas personas que podían pagar el diario, el televisor, la suscripción al cable y el transmisor de radio. El acceso no era universal, pero también tenemos que tener en cuenta que podían ser titulares de medios aquellas personas con respaldo económico para afrontar el gasto inicial o la transferencia de un medio existente.

De acuerdo con una investigación de Ana Silva (2007) los diarios de Tandil y Olavarría en las décadas anteriores a la de 1990, revelan una discursividad orientada hacia el futuro; la tarea que tenían era acompañar el progreso de la ciudad. Los diarios nutren la construcción de las imágenes superpuestas del palimpsesto urbano.

Los mitos fundacionales de los diarios, abordados desde su construcción metadiscursiva en las ediciones aniversario, inscriben sus orígenes en una narrativa de progreso consustancial al cumplimiento del 'destino de grandeza' de las ciudades que los vieron nacer (Silva, 2007: 152).

Ese destino encuentra un límite en la década de 1990. Anteriormente señalamos este momento como de reconversión de los imaginarios, y la autora analiza la aparición de suplementos dedicados a la publicación de fotografías antiguas, que se muestran construidos desde la nostalgia. Los diarios de las ciudades intermedias en sus inicios se inscriben en el progreso proyectado a futuro, y en plena crisis neoliberal miran al pasado, añorando una época de oro de una ciudad deshistorizada (Silva y Gravano, 2017).

En el caso de Olavarría existe un claro ejemplo respecto de quiénes podían emitir bajo esta lógica comercial; en 1982 LU 32 Radio Olavarría comenzó a formar parte del Grupo Fortabat. En la ciudad del cemento la única radio existente -las FM llegarían pocos años más tarde- estaba en manos de la mayor empresa productora de cemento. No podemos analizar el efímero discurso de la radio en las décadas de 1980 y 1990, pero podemos imaginar desde qué lugar se narraron los conflictos obreros, los despidos y la flexibilización laboral.

Los medios de comunicación parecen sostener estos imaginarios que se constituyen en imágenes superpuestas que componen el palimpsesto urbano, los diarios acompañan la construcción de un tribalismo blanco desde sus discursos sobre el progreso, y en la ciudad del cemento el discurso radial formó parte del grupo empresarial fabril durante décadas. 
Como dijimos, la hipótesis de la homeostasis múltiple sostiene que la provisión de servicios públicos de consumo colectivo se piensa desde la presunción de equilibrio y no desde la contradicción dialéctica. En el caso del sistema de medios en el siglo XX en las ciudades intermedias priman las lógicas comerciales. Quienes no tienen los medios económicos, por un lado no pueden acceder a los discursos mediáticos, pero por otro tampoco tienen lugar para emitir mensajes. Desde este "equilibrio normal" se puede suponer que las agendas de temas de medios de comunicación se construyen excluyendo, segregando a los sectores sociales que no tienen recursos económicos.

El surgimiento de las FM abrió el juego a la llegada de nuevos prestadores de servicio de medios de comunicación. La apertura de una radio de ese tipo no requiere una sofisticación tecnológica tan exclusiva y costosa como la de un canal televisivo. Sin embargo los mayores obstáculos de los radiodifusores ha sido regularizar su situación frente a los organismos del Estado. En las ciudades analizadas de la provincia de Buenos Aires, la última apertura de concursos de licencias a prestadores se realizó en 2006. La sanción de la LSCA despertó muchas expectativas al respecto, porque no tener licencia en muchos casos significó tener miedo a que el Estado decomisase los equipos transmisores. Después de la sanción de la nueva normativa se comenzó a avanzar con los concursos en las provincias que menos "desorden" presentaban en el espectro radioeléctrico. Los concursos requieren de un plan técnico que determine cuántas frecuencias están disponibles en cada ciudad y a qué tipo de prestador tienen que ser entregadas ${ }^{6}$. La provincia de Buenos Aires, en su totalidad, fue declarada "zona de conflicto", sin advertir las particularidades de cada ciudad. En primer lugar observamos esta tendencia a suponer que la normalidad es dictada desde el mercado, después de décadas sin regulación estatal. En segundo lugar el estado nacional optó por avanzar en las zonas que no presentaban conflicto, sin observar las urgencias. Los conflictos existieron porque el Estado no brindó la posibilidad de regularizar la situación a los prestadores, pero también esta situación generaba enfrentamientos, distinciones, discusiones entre radiodifusores. Esta situación también es ejemplo de metropolismo: la totalidad de la Provincia de Buenos Aires es entendida como "zona de conflicto" dando por sentado que, por ejemplo, Azul está en la misma situación que el Partido de La Matanza ${ }^{7}$.

\footnotetext{
${ }^{6}$ La LSCA en el Artículo 21 establece 3 tipos de prestadores: Gestión estatal, prestadores con fines de lucro, prestadores sin fines de lucro.

${ }^{7}$ El partido más poblado del Gran Buenos Aires.
} 
La siguiente hipótesis del metropolismo, sostiene que el modelo hegemónico naturaliza una concepción abstracta de lo urbano como idéntico a lo metropolitano. Y vimos un ejemplo expresado en la gestión político institucional de un organismo del Estado nacional.

Con respecto a los medios de comunicación, la centralización geográfica de la producción audiovisual en la Ciudad Autónoma de Buenos Aires da lugar a la dependencia o isomorfismo respecto del imaginario massmediático metropolitano, eventual constructor de modelos hegemónicos que entienden a lo metropolitano como universal. Silva y Gravano señalan que

\footnotetext{
...la dependencia del imaginario hegemónico mediático metropolitano incide en la especificidad del funcionamiento de los sistemas institucionales de consumos colectivos y el cumplimiento de sus propósitos disciplinares, tanto como el sentido común de la cotidianeidad urbana metropolitana transmitida por los medios masivos hegemónicos de difusión y preconcebida como universal se proyecta hacia la ciudad media (2016: 190).
}

Becerra (2014), al analizar la concentración de medios de comunicación en América Latina señala que uno de sus impactos ha sido la centralización geográfica, puesto que la producción de contenidos e informaciones se lleva a cabo en los lugares en los que tienen sede los grandes grupos. En el caso de Argentina los grandes medios se encuentran en la CABA, allí se producen los contenidos que se propalan al resto del país, debilitando el espacio público al verse empobrecida la disposición de diferentes versiones con respecto a lo que sucede.

En la década de 1980 Aníbal Ford se preguntaba si la estructura y el comportamiento de la comunicación, la información y la cultura no serían altamente centralizados y porteños y por eso no aptos para desarrollar una problemática federal que presentase al país en toda su complejidad y riqueza. Ese interrogante, entre otros, lo llevó a analizar datos sobre la televisión, los diarios y las revistas. En el caso de la televisión señalaba la existencia de un alto nivel de concentración en la Capital, entre los 4 canales porteños de aire y el 2 de La Plata alcanzaban al 41\% de la población del país. Respecto de las producciones nacionales el 93\% de las emitidas tenían su origen en Capital Federal. A esto se sumaba que, más allá de la diversidad cultural de la Argentina, las producciones efectuadas en diferentes regiones repetían el modelo capitalino -que a su vez posee un esquema clásico propio de las industrias culturales. La situación empeoraba al detenerse en la inexistente descentralización temática e 
informativa, las producciones referían a las problemáticas de las clases medias porteñas. En referencia a los diarios, el autor señalaba que Capital Federal producía el 65\% de los consumidos en el país. Pero a diferencia de lo sucedido con la televisión, los diarios capitalinos no inundaban el resto del país, porque el 76,8\% eran vendidos en territorio porteño y del Gran Buenos Aires. Sin embargo, se observaba la existencia de un flujo unidireccional porque diferentes regiones del país consumían diarios de Capital pero el Gran Buenos Aires y la ciudad porteña no accedían a diarios del resto del país. Las revistas se producían casi por completo en la ciudad de Buenos Aires (98\%). Capital y provincia de Buenos Aires consumían el 78,1\% de las revistas producidas, tal vez se debía a que sólo un $4 \%$ estaban dedicadas a las problemáticas socioculturales externas al territorio de Capital y Gran Buenos Aires (Ford, 1987).

De acuerdo con el análisis de Ford, en los inicios de la década de 1980 la Capital Federal concentraba la producción en materia de comunicación, información y cultura, la misma no atendía a las problemáticas y necesidades socioculturales del resto del país y los medios de comunicación actuaban unidireccionalmente sobre-informando al país sobre la Capital y desinformando a los porteños sobre el resto del país. Podemos decir que el escenario descripto por Ford, hace aproximadamente 30 años, no ha sufrido grandes modificaciones referidas a la descentralización de la producción (Iturralde, 2015).

Otro ejemplo de metropolismo en las ciudades intermedias se expresa en las agendas de temas de los medios de estas ciudades, que se construyen en base a las agendas de los medios de CABA.

En lo que respecta al sistema de medios de comunicación, habíamos señalado que en América Latina durante el siglo XXI se han planteado algunas rupturas dadas por la sanción de nuevos marcos normativos, y por el posicionamiento del Estado como emisor y gestor de medios. En Argentina se sancionó la LSCA en 2009, y en los años posteriores se vieron modificaciones en los mapas de medios audiovisuales de las tres ciudades analizadas. Una modificación importante fue la división en partes iguales del espectro radioeléctrico entre tres tipos de prestadores: gestión estatal, gestión privada sin fines de lucro y gestión privada con fines de lucro. En el sistema argentino de medios los prestadores con fines de lucro son mayoría. Una de las causas a las que se 
debería, es a que los medios sin fines de lucro estuvieron prohibidos por el artículo 45 de la Ley 22. 285,desde 1980 hasta su modificación en el año $2005^{8}$.

A partir de 2009, mediante diferentes programas del gobierno nacional, se transfieren equipos de radio FM a instituciones educativas y a una cooperativa. También se creó un Polo Audiovisual en Tandil y FM Radio Universidad en Olavarría, ambos dependientes de la Universidad Nacional del Centro de la Provincia de Buenos Aires. Estas acciones se constituyeron en políticas tendientes a crear un sector de medios de comunicación de gestión pública en las ciudades intermedias, al margen de los prexistentes, que se encontraban bajo la órbita de la iglesia católica argentina. En el caso de la cooperativa el objeto era crear un medio privado sin fines de lucro, sector históricamente postergado.

En este momento estamos indagando en cada uno de los casos que entendemos como propios de este proceso de rupturas en el nuevo siglo, y podríamos decir que las políticas del estado nacional suponían que la transferencia de artefactos tecnológicos bastaba para que estos proyectos audiovisuales prosperaran. No se tuvieron en cuenta las situaciones particularidades en las que se inscribían esos medios, y a esto se suma el cambio de gobierno nacional de 2015, que no ha planteado alternativas de continuidad de estos programas. Podríamos decir que el Ejecutivo Nacional, de 2009 a 2015, diseñó políticas que no tuvieron en cuenta las particularidades de las ciudades intermedias, en línea con la hipótesis del metropolismo, pero que también, desde la racionalidad hegemónica, homeostática, se suponía que con la entrega de tecnología se fortalecían los medios sin fines de lucro y de gestión estatal.

En relación a la hipótesis anterior, pero teniendo en cuenta lo que se plantea desde la hipótesis de las tramas de poder, observamos que en 2011 fueron entregadas licencias de radio a los estados municipales de cada ciudad. Tal vez desde el Estado nacional se entendió que la entrega de licencias resultaba un estímulo para la creación de emisoras de frecuencia modulada. Al entrevistar a funcionarios públicos del área de prensa y comunicación de los municipios, respondieron que la apertura de las radios significa un nuevo "gasto" para la Municipalidad, inicial y de mantenimiento posterior. La hipótesis de las tramas de poder permite, por ejemplo, detenerse a observar los vínculos de los gobiernos municipales con los prestadores de medios de comunicación. Hasta el momento podemos mencionar algunos ejemplos que están en etapa de análisis,

\footnotetext{
${ }^{8}$ Ley 26.053
} 
pero bien sirven para verificar la hipótesis. No existen normativas municipales que planteen regulación sobre medios de comunicación, lo que permite sostener un margen de acción vincular muy amplio porque el límite es la normativa nacional. Otro aspecto a destacar es que cualquier persona jurídica puede recibir pauta, el requisito es que esté inscripta como proveedora del estado municipal, pero no es un requisito tener licencia otorgada por el organismo nacional regulador. Y por último se observa que la llegada a las ciudades intermedias de algunos programas del Estado nacional estuvo sujeta a la pertenencia partidaria del gobierno municipal.

\section{Conclusiones}

Los sistemas de medios de comunicación en gran parte de los países de América Latina presentan continuidades y rupturas que pueden ser delimitadas temporalmente. La sanción de nuevos marcos normativos y el cambio de rol del Estado podían constituirse en el inicio de un nuevo rumbo que diera lugar a otra constitución de los mapas de medios de comunicación, permitiendo el ingreso de actores sociales no comerciales que fueron históricamente excluidos.

Lo que estamos analizando desde nuestra investigación son las rupturas del siglo XXI, enumeradas por Becerra (2014), en las ciudades de Azul, Olavarría y Tandil, caracterizándolas como ciudades intermedias. Existen análisis de más de dos décadas efectuados en estos centros urbanos. Resulta importante tomarlos como antecedentes para que las particularidades de las ciudades estén presentes en el análisis.

Si las reflexiones académico-profesionales sobre lo urbano se concentran en los fenómenos que acontecen en las grandes ciudades, si desde el sentido común y la gestión político institucional se reduce lo urbano a lo metropolitano, es nuestro desafío, desde las universidades nacionales y regionales, dar lugar a la construcción de las ciudades intermedias y pequeñas como objeto de análisis.

El objetivo de este trabajo fue centrarnos en las conceptualizaciones sobre ciudades intermedias o de rango medio, sostenidas desde el Núcleo de Producciones e Investigaciones Comunicacionales y Sociales de la Ciudad Intermedia (PROINCOMSCI), para ponerlas en diálogo con los procesos analizados sobre medios de comunicación. Particularmente tomamos las cuatro hipótesis teóricas y las vinculamos a los casos que entendemos como rupturas al tradicional modelo comercial 
de medios de comunicación. Este trabajo, lejos de cerrar el análisis, se presenta como una apertura, como una propuesta para vincular los servicios de comunicación al sistema urbano local.

\section{Referencias}

BECERRA, Martín (2014). Medios de comunicación: América Latina a contramano. Nueva Sociedad, (249), pp. 61-74. Recuperado de http://nuso.org/articulo/medios-decomunicacion-america-latina-a-contramano/

BOGGI, Silvia y GALVÁN, Nora (2016). Ciudad media, ciudad intermedia ¿ni chicha ni limonada?.En: Gravano, A.; Silva, A. y Boggi, S. (Eds.) Ciudades vividas: sistemas e imaginarios de ciudades medias bonaerenses (pp. 25-47). Buenos Aires: Café de las Ciudades.

Congreso de la Nación Argentina (2009). Ley 26.522 de Servicios de Comunicación Audiovisual.

Recuperada de http://servicios.infoleg.gob.ar/infolegInternet/anexos/155000159999/158649/norma.htm

FORD, Aníbal (1987). Aproximaciones al tema de federalismo y comunicación. En Landi, O. (Ed.), Medios transformación cultural y política (pp. 59-87). Buenos Aires, Argentina: Legasa.

GRAVANO, Ariel (2016). Tres hipótesis sobre la relación entre sistema urbano e imaginarios de ciudades medias. En: Gravano, A.; Silva, A. y Boggi, S. (Eds.) Ciudades vividas: sistemas e imaginarios de ciudades medias bonaerenses (pp. 69-90). Buenos Aires: Café de las Ciudades.

ITURRALDE, Maria E. (2015). La descentralización como elemento fundamental en el proceso de democratización de los medios de comunicación en Argentina. Revista Question, 1 (47). Recuperado de http://perio.unlp.edu.ar/ojs/index.php/question/index LLOP TORNÉ, Josep (1999). Ciudades intermedias y urbanización mundial. Lleida, España: UNESCO - UIA. Recuperado de http://www.unesco.org/most/ciudades.pdf MASTRINI, Guillermo (Ed.), Mucho ruido, pocas leyes. Economía y políticas de comunicación en la Argentina (1920-2004) (pp. 185-210). Buenos Aires, Argentina: La Crujía.

SERVAES, Jean (2000). Comunicación para el desarrollo: tres paradigmas, dos modelos. Temas y Problemas de Comunicación, 10, pp. 7-27.

SILVA, Ana y BOGGI, Silvia (2016). Estudios sobre imaginarios de ciudades medias. En: Gravano, A.; Silva, A. y Boggi, S. (Eds.) Ciudades vividas: sistemas e imaginarios de ciudades medias bonaerenses (pp. 49-67). Buenos Aires: Café de las Ciudades.

SILVA, Ana y GRAVANO, Ariel (2016). Gobierno electrónico e imaginarios urbanos: "¿Qué te van a atender por internet en esta ciudad!". En: Gravano, A.; Silva, A. y Boggi, S. (Eds.) Ciudades vividas: sistemas e imaginarios de ciudades medias bonaerenses (pp. 175-192). Buenos Aires: Café de las Ciudades.

SILVA, Ana "Imágenes mediatizadas de la vida urbana. Análisis de casos en dos ciudades de rango medio de la Provincia de Buenos Aires, Argentina". En: Colección de Semiótica Latinoamericana, volumen $\mathrm{N}^{\circ}$ 4: Semiótica de la cultura. Laboratorio de Investigaciones Semióticas y Antropológicas (LISA) de la Universidad del Zulia, Venezuela, 2007. Págs. 139-155. 
SILVA, Ana y GRAVANO, Ariel (2017). Ciudades (medias) y comunicación: cruces, nudos y aperturas. Inmediaciones de la Comunicación. (12) 1, pp. 30-65. Escuela de Comunicación- Universidad ORT: Uruguay. Recuperado de https://revistas.ort.edu.uy/inmediaciones-de-la-comunicacion/issue/view/235/showToc

Recebido em: 20/10/2017. Aprovado em: 15/11/2017. 